\title{
Progestogen-Only Injectable Contraceptives: The Profile of the Acceptors, Side Effects and Discontinuation in a Low Resource Setting, Nigeria
}

\author{
Charles O. Njoku, Cajethan I. Emechebe*, Christopher U. Iklaki, Amarachukwu N. Njoku, \\ Jenkins T. Ukaga \\ Department of Obstetrics \& Gynaecology, University of Calabar Teaching Hospital (UCTH), \\ Calabar, Nigeria \\ Email: *Newlifecj@yahoo.com
}

Received 5 February 2016; accepted 8 March 2016; published 11 March 2016

Copyright (C) 2016 by authors and Scientific Research Publishing Inc.

This work is licensed under the Creative Commons Attribution International License (CC BY). http://creativecommons.org/licenses/by/4.0/

\section{(c) (i) Open Access}

\begin{abstract}
Progestogen-only injectable contraceptive is a highly effective, long lasting and reversible agent of fertility control. The objective is to determine the profile of the acceptors, side effects and indication for discontinuation of progestogen-only injectable contraceptives at UCTH, Calabar. This was a retrospective study of the clients who used progestogen-only injectable contraceptives at the family planning unit between $1^{\text {st }}$ January 2008 and $31^{\text {st }}$ December 2014 . A total of 1392 clients used the injectable progestogen-only contraceptive out of 5986 total contraceptive users giving the prevalence rate of $23.3 \%$ over the period. Of these, $\mathbf{6 0 . 4 \%}$ of the clients accepted the depot medroxyprogesterone acetate, while $39.6 \%$ accepted the norethisterone enanthate. It was mostly utilized by multiparous women, clients with tertiary education and those in their third decade of life. Secondary amenorrhea was the commonest side effect in $47.7 \%$ of the clients. Over the study period, 243 (19.8\%) discontinued the method and $48.1 \%$ discontinued due to secondary amenorrhea while 31.4\% was due to desire to get pregnant. Progestogen-only injectable contraceptive was associated with multiple side-effects, with secondary amenorrhea being the most common, and menstrual irregularity was the main reason for discontinuation. Providing adequate information to clients about this method of contraception and its probable side effects, supportive counseling during initiation of contraception and re-enforcement during follow-up visit can go a long way in enhancing patient satisfaction and hence continuation of progestogen-only injectable contraceptive despite minor side effects.
\end{abstract}

Corresponding author.

How to cite this paper: Njoku, C.O., Emechebe, C.I., Iklaki, C.U., Njoku, A.N. and Ukaga, J.T. (2016) Progestogen-Only Injectable Contraceptives: The Profile of the Acceptors, Side Effects and Discontinuation in a Low Resource Setting, Nigeria. Open Journal of Obstetrics and Gynecology, 6, 189-195. http://dx.doi.org/10.4236/ojog.2016.64024 
Keywords

Injectable, Progestogen, Depot-Provera, Contraceptives, Side Effects, Calabar

\section{Introduction}

Many countries currently face the crises of a rapid growth of human population that has begun to threaten human survival. The voluntary control of fertility therefore became of paramount importance to the modern society. Clinical experience accumulated over recent years indicates that the available progestin-only formulation: depomedroxyprogesterone acetate and norethisterone enanthate are highly effective, long lasting and reversible agents of fertility control, used by up to 20 million women globally [1].

Depo-medroxyprogesterone acetate (DMPA) is a synthetic derivative of progesterone, it is administered at the dose of $150 \mathrm{mg}$ every three months while norethisterone enanthate (NET-EN) is administered at the dose of 200 mg every two months [2]. The mechanism of action is by the suppression of ovulation by interfering with the mid-cycle production of luteinizing hormone and causes morphological changes in the endometrium which renders implantation of the fertilized ovum difficult [2]. It also causes an alteration in the cervical mucus which renders it impervious to spermatozoa hence preventing the ascent of sperm into the uterine cavity.

Progestogen-only injectable contraceptives offer the advantages of not requiring special storage making them suitable for use in the tropical or third world countries like Nigeria [3]. Its use is not obvious and helps women to maintain secrecy about their use of contraception, because members of the families may oppose the concept of birth control [4]. Lactating mothers can successfully breast feed their babies as the progestogen-only injectable contraceptives does not adversely affect milk composition, quality or quantity. They are also independent of intercourse and of the user's memory other than remembering the three or two monthly appointments [3].

Some non-contraceptive benefits of progestogen-only injectable contraceptives have been reported. These include reduction in frequency of sickle cell crises, reduction of menstrual cycle disorders, less dysmenorrhoea, less symptoms of premenstrual tension and reduction in seizure frequency in women with epilepsy [2]. It has also been reported to have effect against epithelial ovarian cancers [5].

Major concerns have also been raised over the long term safety of these agents including the possibility of induction of carcinogenesis, adverse metabolic effects, cardiovascular diseases and osteoporosis. But interestingly and contrary to the fears expressed, no studies to date have demonstrated increase risks of any type of cancers, ischemic heart disease or cerebro-vascular accidents [2] [6]-[10]. Notable side-effects are menstrual disorders including secondary amenorrhea, irregular vaginal bleeding, hypertension, weight gain and menorrhagia [2] [3] [11]. Other reported complications include accidental pregnancies, weight changes, decreased libido, abdominal and chest pains. However, the benefit of its use outweighs the reported complications. Less reported side-effects are psychological and vasomotor disturbances [2] [3]. Long term uses of progestogen-only injectable contraceptives have been reported to reduce bone mineral density [2]. The use of some of these agents is not without adverse effects and complications which may be unacceptable to women therefore resulting in high discontinuation rates in some studies [3] [11]. Health care providers should provide detailed information about the use of this method of contraceptives; the benefit, risks and side effects so that an informed choice can be made.

In view of the effectiveness, safety, convenience and other numerous advantages of injectable progestogenonly contraceptives, it becomes important to determine the pattern of its use in this centre. Hence, the aim of this study is to determine the utilization rate, profile of the acceptors, side effects and the reasons for discontinuation of progestogen-only injectable contraceptive at the University of Calabar Teaching Hospital, Calabar. The findings from this study is expected to help in counseling and encouraging women in the family planning clinic to increase the utilization rate and to reduce the discontinuation in other to benefit maximally from this method of contraception.

\section{Materials and Methods}

This was a seven year retrospective study between $1^{\text {st }}$ January 2008 and $31^{\text {st }}$ December 2014 evaluating the contraceptive usage of only the two forms of progestogen-only injectable contraceptives (medroxyprogesterone acetate and norethisterone enanthate) at the family planning clinic of the University of Calabar Teaching Hos- 
pital. The research protocol fulfilled the criteria for approval by the research ethics committee of the hospital. Data were obtained from family planning records and case files of clients who had used only the two forms of contraceptives for at least two doses for the purpose of contraception. Of the recorded 1392 clients who used progestogen-only injectable contraceptive over the study period, 1226 case files with complete data were available for analysis.

The available case notes of 1226 clients who used injectable medroxyprogesterone acetate and norethisterone enanthate within this period were identified and analyzed. The information obtained was clients' age, parity, marital status, and educational level. Type of injectable progestogen received, reasons for discontinuations and side effects were also obtained. Data analysis was done using Epi info version 3.3.2 software. Data representation was done using frequencies and percentages. Chi-square was used for test of association. Statistical significance was taken at $\mathrm{P} \leq 0.05$.

\section{Results}

A total of 1392 clients used progestogen-only injectable contraceptive out of 5986 total contraceptive users during the study period. This gives the prevalence rate of $23.3 \%$ of total contraceptive users over the period. Among the case notes of 1226 clients available for analysis, 741 (60.4\%) clients accepted depot medroxyprogesterone acetate, while 485 (39.6\%) clients accepted norethisterone enanthate.

Table 1 shows the socio-demographic characteristics of the clients. The age ranged from 17 to 46 years. Progestogen-only injectable contraceptive was utilized mostly by women of 31 - 40 years age group 729 (59.5\%); para 3 - 4 women 926 (75.5\%); married women 1198 (97.7\%) and women with tertiary education 600 (48.9\%).

The commonest side effects were menstrual disorders which include secondary amenorrhea, intermenstrual Spotting/irregular periods and menorrhagia (Table 2). Secondary amenorrhea was the commonest menstrual disorder reported in 493 (47.7\%) of the clients. Some clients reported more than one side effect and all the side effects reported were included in the analysis. The side effect of weight gain was significantly higher among

Table 1. Socio-demographic characteristics of the users.

\begin{tabular}{|c|c|c|c|c|c|}
\hline Variables & Number (\%) & $\begin{array}{c}\text { DMPA (\%) } \\
\text { N = } 741\end{array}$ & $\begin{array}{c}\text { NET-EN (\%) } \\
\quad \text { N = 485 }\end{array}$ & $\mathrm{X}^{2}$ & P-value \\
\hline \multicolumn{6}{|l|}{ Age (years) } \\
\hline$\leq 20$ & $15(1.2)$ & $6(0.8)$ & $9(1.9)$ & \multirow{4}{*}{10.46} & \multirow{4}{*}{0.015} \\
\hline $21-30$ & 414 (33.8) & $243(32.8)$ & 171 (35.3) & & \\
\hline $31-40$ & 729 (59.5) & $440(59.4)$ & 289 (59.6) & & \\
\hline $41-50$ & $68(5.5)$ & $52(7.0)$ & $16(3.3)$ & & \\
\hline $\begin{array}{c}\text { Parity } \\
0\end{array}$ & $7(0.6)$ & $1(0.1)$ & $7(1.4)$ & \multirow{4}{*}{65.89} & \multirow{4}{*}{0.000} \\
\hline $1-2$ & $254(20.7)$ & 199 (28.9) & 55 (11.3) & & \\
\hline $3-4$ & 926 (75.5) & 509 (68.7) & 417 (86.0) & & \\
\hline$\geq 5$ & $39(3.2)$ & $33(4.5)$ & $6(1.2)$ & & \\
\hline \multicolumn{6}{|l|}{ Marital status } \\
\hline Single & $28(2.3)$ & $8(1.1)$ & $20(4.1)$ & \multirow[t]{2}{*}{12.17} & \multirow[t]{2}{*}{0.001} \\
\hline Married & $1198(97.7)$ & 733 (98.9) & 465 (95.9) & & \\
\hline \multicolumn{6}{|l|}{ Educational status } \\
\hline No formal education & $18(1.5)$ & $11(1.5)$ & $7(1.4)$ & \multirow{4}{*}{66.88} & \multirow{4}{*}{0.000} \\
\hline Primary & $143(11.7)$ & $122(16.5)$ & $21(4.3)$ & & \\
\hline Secondary & 465 (37.9) & $226(30.5)$ & 239 (49.3) & & \\
\hline Tertiary & 600 (48.9) & 382 (51.5) & $218(45.0)$ & & \\
\hline
\end{tabular}

DMPA = Depot medroxyprogesterone acetate; NET-EN = Norethistherone enantate. 
clients who used injectable medroxyprogesterone acetate compared to norethisterone enanthate in this study $\left(\mathrm{X}^{2}=\right.$ 4.90; $\mathrm{df}=1 ; \mathrm{P}=0.027)$.

A total of 243 (19.8\%) clients discontinued the method over the study period. Some of the clients reported more than one reason for discontinuation. The commonest reason for discontinuation was due to secondary amenorrhea 117 (48.1\%) while 76 (31.4\%) clients discontinued because of desire to get pregnant (Table 3).

\section{Discussion}

Family planning is necessary for spacing of children, prevent unwanted pregnancy, limit the family and curb undesired population growth. Progestogen-only injectable contraceptive is the second commonly used method of family planning among women attending family planning clinic in UCTH [12]. The use prevalence of this widely accepted contraceptive method in this study was $23.3 \%$. This is comparable to $22.1 \%$ reported in Osogbo (south western Nigeria) [3] and 21.9\% reported in Ilorin (north central Nigeria) [13]. It is higher than $14.2 \%$ reported from Jos (north central Nigeria) [14]. It is lower than the $41.0 \%$ and $50.7 \%$ reported from Port Harcourt (south south Nigeria) [15] and Zaria (north western Nigeria) [16], respectively. In general, there seems to be regional variation in the use prevalence of progestogen-only injectable contraceptive. This regional variation may be as a result of cultural and religious beliefs, contraceptive counseling skills and individual client's perception of the contraceptive methods.

Table 2. Side effects/complications from users of progestogen-only injectable contraceptives.

\begin{tabular}{cccccc}
\hline Side effects & Number (\%) & DMPA (\%) & NET-EN (\%) & $\mathbf{X}^{\mathbf{2}}$ & P-value \\
\hline Secondary amenorrhea & $585(47.7)$ & $366(49.4)$ & $219(45.2)$ & 2.11 & 0.146 \\
Intermenstrual Spotting/irregular periods & $280(22.8)$ & $167(22.5)$ & $113(23.3)$ & 0.10 & 0.756 \\
Menorrhagia & $39(3.2)$ & $25(3.4)$ & $14(2.9)$ & 0.23 & 0.635 \\
Hypertension & $32(2.6)$ & $21(2.8)$ & $11(2.3)$ & 0.37 & 0.543 \\
Injection abscess & $2(0.19)$ & $2(0.3)$ & $0(0.0)$ & - & - \\
Weight gain & $153(12.5)$ & $105(14.2)$ & $48(9.9)$ & 4.90 & 0.027 \\
Weight loss & $1(0.07)$ & $0(0.0)$ & $1(0.2)$ & - & - \\
Headache & $25(2.0)$ & $14(1.9)$ & $11(2.3)$ & 0.21 & 0.646 \\
Decreased libido & $21(1.7)$ & $15(2.0)$ & $6(1.2)$ & 1.08 & 0.299 \\
Dizziness & $11(0.9)$ & $7(1.0)$ & $4(0.8)$ & 0.05 & 0.828 \\
Mastodynia & $15(1.2)$ & $11(1.5)$ & $4(0.8)$ & 1.06 & 0.304 \\
Abdominal/waist pain & $18(1.5)$ & $12(1.6)$ & $6(1.2)$ & 0.30 & 0.586 \\
Vulvovaginitis & $4(0.3)$ & $3(0.4)$ & $1(0.2)$ & 0.38 & 0.551 \\
\hline
\end{tabular}

Table 3. Reasons for discontinuation of progestogen-only injectables contraceptive $(n=243)$.

\begin{tabular}{|c|c|c|}
\hline Reasons & Frequency & Percentage (\%) \\
\hline Secondary amenorrhea & 117 & 48.1 \\
\hline Desire to get pregnant & 76 & 31.4 \\
\hline Weight gain & 24 & 9.8 \\
\hline Spotting/intermenstrual bleeding & 19 & 7.8 \\
\hline Hypertension & 18 & 7.4 \\
\hline Discomforts of injections & 5 & 2.0 \\
\hline Pregnancy while on contraception & 2 & 0.8 \\
\hline Not specified & 6 & 2.5 \\
\hline
\end{tabular}


Women in this study utilized depot medroxyprogesterone acetate injectables more than norethistherone enantate injectables. The reason for preferring the 3-monthly injection may be due to the reduced frequency of visits to the provider and reduction in frequency of injections. Frequent appointment may be perceived as economic loss from transportation and time loss. This is consistent with previous reports from other parts of Nigeria [3] [13].

The age range of the clients was 17 - 46 years, with a mean of $31.29 \pm 5.3$ years. The young adolescent (age: 19 years and below) were least among clients who utilized progestogen-only injectable contraceptives. This may be due to low contraceptive rate among teenagers or its side effects such as amenorrhea and effect on the bone mineral density [3]. Other reason for this low usage among teenagers could be that service providers may discriminate against teenagers and fear of parental knowledge and disapproval [17]. Such clients may shy away from these facilities since they do not want to be seen as promiscuous because of the general myth that associates use of contraceptives with sexual permissiveness.

The trend of parity among the studied population revealed that injectable contraceptives were used mostly by multiparous women than nulliparous women and this is in agreement with a previous study [13]. The reason for this may be due to the fact that more multiparous women seek for contraception [3] [11] and nulliparous women would benefit more from barrier methods which will give them dual protection (against pregnancy and sexually transmitted infections). Most of the clients $98.5 \%$ had at least primary education, and majority of the users 48.9\% had tertiary education. Education and understanding the contraceptive counseling may have informed the choice of this contraceptive method among clients with tertiary education. This is similar to the findings of some authors in sub-Saharan Africa [3] [11].

Menstrual disorders were the commonest side effects experienced by the study subjects. Secondary amenorrhea was the most common menstrual disturbances reported by $47.7 \%$ of the clients which was comparable to other studies [3] [11]. The other disturbances of menstruation encountered in this study include menorrhagia $3.2 \%$, irregular menstruation/intermenstrual spotting occurred in $22.8 \%$. The menstrual disorders are due to the effect on ovarian function. Fluctuating endogenous oestrogen production from irregular follicular growth leads to irregular bleeding whereas the secondary amenorrhea has been attributed to ovarian suppression and endometrial atrophy [2] [18]. There is belief that progestogen-only injectable contraceptive persist in the body for several months in women who have used it for long-term contraception, and return to fertility may be delayed. Because of the high effectiveness of progestogen-only injectable contraceptives to suppress ovulation, there is a significant delay in return to fertility after discontinuation. This method is only temporary contraceptives with a substantial delay in return to fertility [2] [3] [18]. Some non-menstrual side effects also occurred among the study population and included weight gain in $12.5 \%$, hypertension in $2.6 \%$, vulvovaginitis in $0.3 \%$. Continued use of progestogen-only injectable contraceptive depends on the ability of the client to accept and adapt to changes in her menstrual pattern and to tolerate other side effects.

The discontinuation rate of $19.8 \%$ observed in this study was similar to the previous report from this centre [12] but very high compared to 6.1\% reported in Nnewi, Nigeria [11]. Factors such as clients’ preference, education, provider's experience, knowledge and counseling on the side effects could have contributed to the differences observed in discontinuation rate in these studies. Menstrual abnormality was the commonest reason for discontinuation of this effective method of contraception by our women, and this is similar to some previous studies [3] [19] [20]. Most women are conscious of their pattern of menstruation and how it affects their lives. Perceptions of menstruation vary in different cultures and religions. This perception may influence the attitudes and reactions of women to changes in bleeding pattern resulting from the use of this hormonal contraceptive. Abnormal vaginal bleeding is socially inconvenient to clients and many women have expressed concerns over their fertility, inability to perform religious rites and meet their coital obligations to their partners as a consequence. This may be the reasons for high discontinuation rate due to menstrual irregularities.

\section{Conclusion and Recommendation}

Progestogen-only injectable contraceptive was commonly utilized among women with tertiary education, multiparous and women in third decade of life. It was associated with multiple side-effects, with secondary amenorrhea being the most common. The main reason for discontinuation was due to menstrual irregularity. Education of the women should be pursued with vigor. Providing adequate information to clients about this method of contraception and its probable side-effects, supportive counseling during initiation of contraception and re-enfor- 
cement during follow-up visit can go a long way in enhancing patient satisfaction and hence continuation of progestogen-only injectable contraceptive despite minor side-effects.

\section{Limitations of the Study}

The limitations to this study were the retrospective nature of the study and being a hospital based study. As with retrospective studies, any missing patient record affects the reliability of the data. However, the review assisted in addressing the research questions and in providing information that can be used for further studies and in training contraceptive providers in our setting.

\section{Conflict of Interest}

The Authors declare that there is no conflict of interests regarding the publication of this paper.

\section{Funding Information}

The researchers did not receive grant from any funding agency in the public and commercial sectors.

\section{References}

[1] Adaji, S.E., Shittu, S.O. and Sule, S.T. (2005) Attitude of Nigerian Women to Abnormal Menstrual Bleeding from Injectable Progestogen-Only Contraceptive. Annals of African Medicine, 4, 144-149

[2] Burkman, R. and Amnon, B. (2013) Contraception and Family Planning. In: Decheney, A.H., Ed., Current Diagnosis and Treatment Obstetrics and Gynaecology, Lange Medical Book, McGraw-Hill Companies, New York, 928-947.

[3] Adeyemi, A.S. and Adekanle, D.A. (2012) Progestogen-Only Injectable Contraception: Experience of Women in Osogbo, Southwestern Nigeria. Annals of African Medicine, 11, 27-31. http://dx.doi.org/10.4103/1596-3519.91013

[4] The ESHRE Workshop Group (2003) Birth Control. Human Reproduction Update, 9, 373-86.

[5] Wilailak, S., Vipupinya, C., Suraseranivong, V., Chotivanich, K., Kietpeerakool, C., Tanapat, Y., et al. (2012) Depot Medroxyprogesterone Acetate and Epithelial Ovarian Cancer: A Multicentre Case-Control Study. BJOG, 119, 672677. http://dx.doi.org/10.1111/j.1471-0528.2012.03298.x

[6] Li, C.I., Beaber, E.F., Tang, M.T., Porter, P.L., Daling, J.R. and Malone, K.E. (2012) Effect of Depot-Medroxprogesterone Acetate on Breast Cancer Risk among Women 20 to 44 Years of Age. Cancer Research, 72, 28-35.

[7] Hermsmeyer, R.K., Thompson, T.L., Pohost, G.M. and Kaski, J.C. (2008) Cardiovascular Effects of Medroxyprogesterone Acetate and Progesterone: A Case of Mistaken Identity? Nature Clinical Practice Cardiovascular Medicine, 5, 387-395. http://dx.doi.org/10.1038/ncpcardio1234

[8] Ezegwui, H.U., Ikeako, L.C. and Obiora-Okafor, N.C. (2012) The Use of Depot Medroxyprogesterone Acetate Injectable Contraception in Enugu, Nigeria. Nigerian Medical Journal, 21, 266-271.

[9] Mia, A.R., Siddiqui, N.I., Islam, M.N., Khan, M.R., Shampa, S.S. and Rukunuzzaman, M. (2005) Effects of Prolonged Use of Injectable Hormonal Contraceptive on Serum Lipid Profile. Mymensingh Medical Journal, 14, 19-21.

[10] Afsar, N.A., Barakzai, Q. and Adil, S.N. (2004) Use of Northisterone Enathate and Predisposition to Thrombosis. Journal of College of Physicians and Surgeons Pakistan, 14, 556-559.

[11] Igwegbe, A.O. and Ugboaja, J.O. (2010) Clinical Experience with Injectable Progestogen-Only Contraceptives at Nnamdi Azikiwe University Teaching Hospital, Nnewi, Nigeria. Journal of Medicine and Medical Sciences, 1, 345349.

[12] Njoku, C.O., Emechebe, C.I., Agbarakwe, H., Ekabua, J.E. and Abeshi, S. (2014) Utilization and Discontinuation of Contraceptive Methods: The UCTH Experience. Population, 5, 6.

[13] Balogun, O.R. and Raji, H.O. (2009) Clinical Experience with Injectable Progestogen-Only Contraception at University of Ilorin Teaching Hospital: A Five-Year Review. Nigerian Postgraduate Medical Journal, 16, 260-263.

[14] Mutihir, J.T. and Pam, V.C. (2008) Overview of Contraceptive Use in Jos University Teaching Hospital, North Central Nigeria. Nigerian Journal of Clinical Practice, 11, 139-143.

[15] Chigbu, B., Onwere, S., Aluka, C., Kamanu, C., Okoro, O. and Feyi-Waboso, P. (2010) Contraceptive Choices of Women in Rural Southeastern Nigeria. Nigerian Journal of Clinical Practice, 13, 195-199.

[16] Ameh, N. and Sule, S.T. (2007) Contraceptive Choices among Women in Zaria, Nigeria. Nigerian Journal of Clinical Practice, 10, 205-207.

[17] Okpani, A.O.U. and Okpani, J.U. (2000) Sexual Activity and Contraceptive Use among Female Adolescent-A Report 
from Port Harcourt, Nigeria. African Journal of Reproductive Health, 4, 40-47.

[18] Lisa, M. and Melissa, G. (2008) Contraception. In: Gibbs, R.S., Ed., Danforth’s Obstetrics and Gynecology, Lippincott Williams \& Wilkins, Philadelphia, USA, 567-585. http://dx.doi.org/10.2307/3583241

[19] Ojule, J.D., Orji, V.K. and Okongwu, C. (2010) A Five-Year Review of the Complications of Progestogen only Injectable Contraceptive at the University of Port-Harcourt Teaching Hospital. Nigerian Journal of Medicine, 19, 87-95. http://dx.doi.org/10.4314/njm.v19i1.52487

[20] Stubblefield, P.G. (2002) Family Planning. In: Berek, J.S., Ed., Novak’s Gynecology, Lippincott Williams and Wilkins, Los Angeles, California, 18-19. 